\title{
OXCARBAZEPINE AND SPASTICITY
}

\author{
FURTHER OBSERVATIONS
}

PAULO ROGERIO M. BITTENCOURT A

\begin{abstract}
SUMMARY - The previously described anti-spastic effect of oxcarbazepine and $10,11-d i h y d r c$ 10-hydroxycarbamazepine was found accidentally in 2 patients undersoing a double-blind comparative study 1or evaluation of antiepileptic effect. In this study oxcarbazepine was given orally in doses of $300-2700 \mathrm{mg}$ daily to one patient with transverse myelitis and to two patients with multiple sclerosis, all of whom had clinically disabling spasticity in the form of difficulty in walking, lower limb rigidity, spastic contractions of the lower limbs and ankle clonus. Anti-spastic effect was observed at doses between $600-1200 \mathrm{mg}$ daily and consisted in a substantial decrease in the above symptoms of spasticity. The anti-srastic effect appears at a dose immediately below that which produces nausea, dizziness and scmnolence.
\end{abstract}

\section{Oxcarbazepina e espasticidade: observagões clínicas.}

RESUMO - O efeito antiespástico da oxcarbazepina e de 10,11 diidro-10-nidroxicarbamazepina foi anteriormente descrito em dois pacientes em estudo duplo-cego comparativo do efeito antiepilépticu dessas drogas. No presente estudo oxcarbazepina foi administrada oralmente em doses de $300-2700 \mathrm{mg} / \mathrm{dia}$ a um paciente com mielite transversa e a dois pacientes com esclerose múltipla, todos com espasticidade clinicamente incapacitante na forma de dificuldade de marcha, rigidez de membros inferiores, contraçōes espásticas de menbros inferiores e clono aquileu. O efeito antiespástico foi observado em doses entre $600-1200 \mathrm{mg} / \mathrm{dia} \epsilon \mathrm{con}-$ sistiu de diminuição substancial nos sintomas de espasticidade acima descritos. $O$ efeito antiespástico apareceu em doses imediatamente abaixo daquelas que produzem náusea, tontura e sonolência.

The anti-spastic effect of oxcarbazepine and 10,11-dihydro-10-hydroxicarbamazepine was found accidentally in two patients undergoing a double-blind comparative study of the two drugs for the control of epileptic seizures 1 . Both patients had porencephalic epileptogenic lesions which accounted for the spasticity.

In order to ascertain whether oxcarbazepine had an independent anti-spastic effect three further patients were evaluated.

\section{METHODS}

Patients were chosen on the basis that clinically measurable spasticity was an impurtant source of disability or discomfort and needed specific therapy. Difficulty in walking, limb rigidity, clonus and spastic contractions of the limbs were considered amenable to examiner and patient assessment.

* M.D., Ph.D; Unidade de Neurologia Chnica, Hospital Nossa Senhora das Graças, Curitiba. 
Oxcarbazepine tablets (300 $\mathrm{mg}$, Ciba-Geigy, Switzerland) were given orally three times daily in progressive doses until patients felt the customary side-effects of nausea, diplopla, dizziness and ataxia. The dose was then settled at a level just below that which producod toxicity.

\section{RESULTS}

Case 1 - JAL, born 1962. was admitted in September 1985 because of paraparesis and urinary retention, with a T10 sensory level to pin-prick. A diagnosis of transverse myelitis was based on myelography, visual and auditory evoked potencials, CSF studies and other routine examinations. He had suffered cranio-cerebral trauma in 1983 which resulted in anosmia and an amaurosis with bilateral optic atrophy and no other signs of CNS involvement. When admitted again in January 1986 he had a spastic paraplegia with a T10 sensory level to pin-prick, spastic bladder and severe lower limb spasticity with frequent spontaneous ankle clonus, rigidity and spastic contractions. Oxcarbazepine was started at a dose of $600 \mathrm{mg}$ daily and 6 days later he was discharged on a dose of $2700 \mathrm{mg}$. No other drugs were used. The dose was decreased to $1200 \mathrm{mg}$ daily due to nuusea, vomitting and dizziness. On review in April 1986 he reported great improvement in spasticity, with no spontaneous ankle clonus, decreased rigidity and infrequent spastic contractions. The patient began to walk aided by his family. In June 1986 sensory examination had improved and he could walk a few steps with aid. Oxcarbazepine was withdrawn progressively over a period of 4 weeks in August 1986 without significant neurological changes.

Case 2 - MY, born 1943, first developed rheumatoid arthritis in 1975 followed in 1978 by a «brainstem encephalitis». Over the next 7 years she had at least three episodes r.f optic neuritis and three of spastic tetra or paraparesis which left her almost blind and confined to bed by 1985. In 1982 Sjogren's syndrome had been diagnosed. When admitted in July 1985 rheumatoid arthritis was active and there were left optic atrophy, right-sided pallor of the optic disc, spastic tetraparesis with inability to move, absent sensation to vibration or joint position and a T8 (left) and T10 (right) sensory level tu pin-prick. CSF studies and visual, auditory and somatosensory evoked responses confirmed a diagnosis of multiple sclerosis. After treatment with azathioprine, prednisone and baclofen there was great neurological improvement with remission of arthritic symptoms and by Octoper 1985 she could walk with braces. Vision and bladder control were improved enough for her to resume limited social activities. By January 1986 she could take a few steps unaided, sensory levels to pain were L1 (left) and L3 (right) and position sensation was absent only in the lower limbs. Re-examination of evoked responses showed evidence of thoracolumbar spinal cord lesion (s). At this stage she was on baclofen (30 mg), amitriptiline $(50 \mathrm{mg})$ and azathioprine $(150 \mathrm{mg})$ daily and on prednisone $(60 \mathrm{mg})$ in alternate days. Lower-limb spasticity in the form of rigidity, spontaneous ankle clonus and spastic contractions occurring more intensely in the evening were her most urgent complaints. Baclofen was slowly replaced by oxcarbazepine over a 2-week period. The dose of uxcarbazepine was tailored at $900 \mathrm{mg}$ daily as more produced somnolence and dizziness. By March 1986 rigidity had decreased significantly, clonus could only be obtained by persistent stimulation and lower limb spastic contractions occurred only rarely. When seen in June and October 1986, walking had improved to the extent that she only needed crutches outside her home. During 1986 prednisone was further decreased to $15 \mathrm{mg}$ in alternate days. Oxcarbazepine was decreased to $600 \mathrm{mg}$ daily and finally tapared off in December 1986 without noticeable neurological changes.

Case 3 - NM, born 1934, was well until age 19 when she developed a paraparesis followed over the next 30 years by a slowly progressive neurological disorder punctuated by exacerbations characterized by visual disturbances and tetraparesis. When admitted in 1983 she had bilateral optic disc pallor, spastic tetraparesis more pronounced on the right and in the lower limbs, generalized moderate ataxia, absent vibration sense to the iliac crests but pin-prick was apparently maintained. Spasticity was prominent with rigidigy, spontaneous ankle clonus and spastic contractions of the lower limbs mainly when in bed. CSF studies and visual and auditory evoked responses confirmed a diagnosis of multiple sclerosis. Diazepam was attempted for treating spasticity (5 $\mathrm{mg}$ daily) but produced worsening of pre-existing depression and was withdrawn. Imipramine was started (75 mg daily). Slow but progressive neurological deterioration continued throughout 1987 eventhcugh azathioprine was used since November 1984 and prednisone was added from May 1985 . She was only able to take a few steps at home with the help of special rails fitted to her 
apartment. In March 1986 oxcarbazepine was started at a dose of $300 \mathrm{mg}$ daily with subsequent improvement in spastic rigidity and decrease of spastic contractions. Clonus became present only when provoked. Upon an attempt at increasing the dose of oxcarbazepine to $600 \mathrm{mg}$ and then inadvertedly to $900 \mathrm{mg}$ daily, she developed somnolence, dizziness and the spastic paresis became flacid. This made it impossible for her to walk and she refused to continue oxcarbazepine. On examination at this occasion the lower limb spasticity has practically disappeared.

\section{COMMENTS}

These uncontrolled observations in complex patients offer limited scope for definite conclusions. Nonetheless, oxcarbazepine had a definite anti-spastic effect which was much quicker in onset immediately after its initiation than the improvement observed in other neurological functions in patients undergoing spontaneous improvement (case 1) and improvement induced by prednisone and azathioprine (case 2). Patients and physicians agreed to this effect and the drug was withdrawn only because supplies finished. Case 3 was deteriorating progressively and slowly when oxcarbazepine was started and the anti-spastic effect was not only dramatic but also excessive.

The anti-spastic effect of oxcarbazepine was documented by objective decrease in rigidity, clonus and spastic contractions, always in the lower limbs. Case 1 had an isolated thoracic spinal cord lesion, cases 2 and 3 had similarly located cord lesions documented clinically and/or by somato-sensory evoked responses. The measures of spasticity used are indicative of dysfunction caused by these lesions. These observations indicate that oxcarbazepine is anti-spastic not only for epileptogenic cerebral lesion 1 but also for spinal cord lesions. Further controlled studies in greater number of patients are warranted to establish the clinical usefulness and dose ranges of this new anti-spastic agent as well as its comparative efficacy in relation to other available medications.

\section{REFERENCIA}

1. Bittencourt PRM, Silvado CES - Oxcarbazepine, GP 47779, and spasticity. Lancet 2: 676, 1985. 